\title{
Microbial Resources and Innovation in the Wine Production Sector
}

\author{
C. Berbegal ${ }^{1}$, G. Spano ${ }^{1 *}$, M. Tristezza ${ }^{2}$, F. Grieco ${ }^{2}$, V. Capozzi ${ }^{1}$
}

(1) Dipartimento di Scienze Agrarie, degli Alimenti e dell'Ambiente, Università di Foggia, via Napoli 25, 71122, Foggia, Italy

(2) Istituto di Scienze delle Produzioni Alimentari, Consiglio Nazionale delle Ricerche, Unità Operativa di Supporto di Lecce, Lecce, Italy

Submitted for publication: November 2016

Accepted for publication: June 2017

Key words: Starter cultures

\begin{abstract}
Microbial starter cultures represent a fundamental level of innovation in the wine sector. Selected yeast strains are routinely used to achieve the needed biomass preparation to accelerate and steer alcoholic fermentation in grape must. The use of starter cultures to induce malolactic fermentation in wine relies on the characterisation and propagation of suitable strains of lactic acid bacteria. Furthermore, the selection of new strains, the renewal of management of microbial resources and new technologies allow continuous improvements in oenology, which may increase the beneficial aspects of wine. In this review, with the aim to stimulate microbial-driven, consumer-oriented advances in the oenological sector, we propose an overview of recent trends in this field that are reported by following the classical separation into 'product innovation' and 'process innovation'. Hence, we shall highlight i) the possible positive innovative impacts of microbial resources on the safety and the sensorial and functional properties of wine (product innovation) and ii) the potential microbial-based improvements allowing the reduction of time/costs and the environmental impacts associated with winemaking (process innovation).
\end{abstract}

\section{INTRODUCTION}

The winemaking process is the set of operations and practices carried out to transform grape must into wine by respecting the intrinsic qualities of grapes in order to obtain the best final product. The indigenous microbiota is very important in this winemaking process because of its possible positive or negative effects on wine quality. In particular, yeasts, mainly Saccharomyces cerevisiae, are essential for carrying out the alcoholic fermentation (AF), thus promoting the transformation of grape sugars into ethanol, carbon dioxide and hundreds of other metabolites (Garofalo et al., 2016a). However, $S$. cerevisiae is not the only yeast involved in the process. Selected specific non-Saccharomyces species have been proven to positively modify the chemical composition of the wine, contributing especially to the sensory properties of wines (Bely et al., 2008; Comitini et al., 2011; Liu et al., 2016; Petruzzi et al., 2017a). In contrast, lactic acid bacteria (LAB) perform the malolactic fermentation (MLF). The main value of the MLF in vinification is biological de-acidification (i.e. increase in $\mathrm{pH}$ ), which results from the transformation of L-malic acid into L-lactic acid (Bauer \& Dicks, 2004; Lerm et al., 2010). Moreover, the MLF contributes to microbiological stability and produces a change in wine aroma and mouthfeel (Lerm et al., 2010).

Given the significant progress in the wine sector concerning different microbiological aspects, in this review we shall provide an overview of the recent trends, categorised into product innovation and process innovation (for specific definitions please refer to OECD 2015, available at http:// www.oecd.org/site/innovationstrategy/defininginnovation. htm). Such innovation is prompted partially by the current importance of the organic food regimen and of the associated emerging trends. Indeed, worldwide interest in organic farming has increased significantly over the last decade. Wine is no exception to this trend, as consumers are demanding organic wines and environmental friendly viticultural practices (Provost \& Pedneault, 2016), the reduction of the total price of biotechnological processes, and environmentally friendlier methods for disposing of winemaking process waste products (Devesa-Rey et al., 2011). Organic wine production aims at producing a product with a high final quality while minimising the use of synthetic chemicals such as fertilisers, pesticides,

\footnotetext{
*Corresponding author: E-mail address: giuseppe.spano@unifg.it [Tel.: +39 (0)881 589303; Fax: +39 (0)881 740211$]$

Acknowledgements: This research was supported by the Apulia Region within the framework of the Projects "Sviluppo di approcci microbiologici innovativi per il miglioramento della qualità di vini tipici Regionali - NEWINE (Bando "Ricerca e sperimentazione in Agricoltura"; Project code PRS 042), "Biotecnologie degli alimenti per l'innovazione e la competitività delle principali filiere regionali: estensione della conservabilità e aspetti funzionali - BIOTECA” (Bando "Aiuti a Sostegno Cluster Tecnologici Regionali"; Project code QCBRAJ6) and "Innovazioni di processo e di prodotto nel comparto dei vini spumanti da vitigni autoctoni pugliesi" - IPROVISP (Bando "Aiuti a Sostegno Cluster Tecnologici Regionali”; Project code VJBKVF4). Vittorio Capozzi was supported by Fondo di Sviluppo e Coesione from 2007 to 2013 - APQ Ricerca Regione Puglia "Programma regionale a sostegno della specializzazione intelligente e della sostenibilità sociale ed ambientale - FutureInResearch". Carmen Berbegal was supported by "Subprograma Atracció de Talent 2015 de la Universitat de València"
} 
fungicides and herbicides. The terroir that represents the basis of the Appellation of Origin also produces an impact on the wine market and on consumer choices (Capozzi et al., 2015). Therefore, many investigations are pointing in that direction. Moreover, because of the importance of healthy food with functional properties, research is focusing on the biochemical activities of grape and wine not only as prospective sources of valuable nutraceuticals, but also for their antimicrobial activity and for other biological functions such as the modulation of the endogenous antioxidant system (Giovinazzo \& Grieco, 2015).

In this review we will discuss the recent developments in microbial resources regarding the selection of autochthonous cultures, also addressing the integration of non-Saccharomyces yeasts into the design of mixed starters. We will summarise the most recent investigations of biocontrol as a tool for the quality of safety to prevent the contamination of the microorganisms by spoilage microbes and to reduce the content of toxic compounds in wine. We will also discuss some recent biotechnological approaches, viz. the co-inoculation of yeast and LAB and the immobilisation of microorganisms aimed at reducing the duration and cost of the winemaking process.

\section{PRODUCT INNOVATION}

\section{Microbial-based sensorial quality enhancement Yeast starters for alcoholic fermentation}

Even though the entire wine microbiota contributes to the wine chemistry, the yeasts play a predominant role since they promote the AF and also produce several secondary metabolites that contribute strongly to the organoleptic properties of the wine (Fleet, 2008). Commercial starter cultures of $S$. cerevisiae are routinely used to i) accomplish the AF, ii) produce desirable metabolites and iii) avoid the possible negative effects associated with the development of indigenous microorganisms and/or with spontaneous fermentations (Belda et al., 2017; Spano et al., 2010; Capozzi \& Spano, 2011; Tristezza et al., 2013). Nevertheless, in some cases there are advantageous oenological traits associated with spontaneous fermentations, such as the development of a specific sensory character. On the other hand, the use of a reduced number of commercial starter cultures could cause standardisation, hence flattening wine quality (Fleet, 2008). In this context, the use of multi-strain starter cultures designed with autochthonous microbial resources (e.g. non-Saccharomyces yeasts combined with $S$. cerevisiae in controlled mixed fermentations), mimicking the natural diversity associated with spontaneous fermentation, can be recommended to improve wine (Comitini et al., 2011; Ciani \& Comitini, 2015; Campbell-Sills et al., 2016; Shekhawat et al., 2017). In this regard, the non-Saccharomyces species, Torulaspora delbrueckii, Metschnikowia pulcherrima, Candida zemplinina and Hanseniaspora uvarum, are cited and intensively investigated the most (Comitini et al., 2011; Medina et al., 2012; Masneuf-Pomarede et al., 2015; Petruzzi et al., 2017a), while strains belonging to the species Lachancea thermotolerans, Metschnikowia fructicola, Schizosaccharomyces pombe, T. delbrueckii, Kluyveromyces thermotolerans, Pichia kluyveri and M. pulcherrima are already commercialised (Lu et al., 2016; Petruzzi et al., 2017a).

Numerous studies on the influence of nonSaccharomyces yeast in winemaking have been undertaken on the oenological/technological relevance of these yeast species (Bely et al., 2008; Comitini et al., 2011; Sadoudi et al., 2012; Tristezza et al., 2016b; Petruzzi et al., 2017a). These studies demonstrated that non-Saccharomyces species could have both beneficial and negative influences on the wine fermentation characteristics, thus indicating the need to select strains with optimal oenological properties (Bely et al., 2008; Comitini et al., 2011; De Benedictis et al., 2011; Medina et al., 2012; Lu et al., 2015; Petruzzi et al., 2017a). Indeed, several non-Saccharomyces species have been proven to positively modify the wine chemical composition, contributing especially to the sensory properties of wines (Jolly et al., 2014; Oro et al., 2014; Lu et al., 2015; Petruzzi et al., 2017a). However, the growth of certain non-Saccharomyces strains in grape musts can cause the development of antagonistic interactions among yeasts and lead to an excessive accumulation of several undesirable metabolites, such as acetic acid, ethyl acetate, aldehyde and acetoin (Medina et al., 2012; Ciani et al., 2016; Liu et al., 2017), and other phenotypic properties in some cases also characteristic to $S$. cerevisiae strains from alcoholic beverages (Capozzi et al., 2016b). Some non-Saccharomyces species even exhibit low fermentation power and rate, as well as low ethanol and $\mathrm{SO}_{2}$ resistance (Medina et al., 2012; Tristezza et al., 2013; Alonso et al., 2015).

Over the last years an increasing demand for "organic wine" (produced according to the European Commission Implementing Regulation (EU) No 203/2012 of March 8th 2012) has been observed (Guzzon et al., 2011; Suzzi et al., 2012; Francesca et al., 2016). Moreover, there has been a rising request for autochthonous yeast starter cultures, since they can be used in the making of organic wines. These autochthonous starters are potentially adapted to a definite grape must and reflect the biodiversity of a particular area, which supports the idea that indigenous yeast strains can be associated with a "terroir" (Gilbert et al., 2014; Capozzi et al., 2015). In this context, many investigations have studied the biodiversity of $S$. cerevisiae and nonSaccharomyces yeasts in a regional area in order to select autochthonous starters distinguished by different oenological characteristics (Capozzi et al., 2015; Garofalo et al., 2016a; Tristezza et al., 2016b). Organic wine processing may be more challenging than that of conventional wine, especially under regulations prohibiting $\mathrm{SO}_{2}$. A number of compounds have been tested in order to replace $\mathrm{SO}_{2}$ in wine, such as wine bacteriocins, chitosan and lysozyme (Díez et al., 2012; Bagder Elmaci et al., 2015; Ancì-Azpilicueta et al., 2016), and several physical methods have been tested, including pulsed electric fields and high hydrostatic pressure (Santos et al., 2013). However, none of these practices provided a real replacement for $\mathrm{SO}_{2}$, or its use is not allowed in organic wine production (Guerrero \& Cantos-Villar, 2015). In order to reduce the production of oxidative off-flavours during non-sulphated organic winemaking, Balboa-Lagunero et al. (2013) suggested carrying out the AF using autochthonous 
S. cerevisiae strains from the Origin Appellation "Vinos de Madrid", showing high consumption rates of amino acids known to act as precursors for oxidation attributes in wine. Certain yeast strains successfully reduced the occurrence of oxidation-related aldehydes as well as the intensity of off-flavours in wine made without sulphites. Taken together, the above findings highlight the importance of the characterisation of the autochthonous microbiota and the integration of non-Saccharomyces strains in the design of autochthonous resources for sustainable and coherent innovations in the wine sector. In addition, the formulation of non-Saccharomyces with Saccharomyces starters could be a reliable alternative to spontaneous uncontrolled fermentations in organic wines. Nowadays, mixed cultures of Saccharomyces and non-Saccharomyces from commercial yeast manufacturers are available, such as Level $^{2}$ TD (Lallemand Inc., France) and Melody TM (Chr Hansen, Denmark).

In the case of sparkling wine, two successive steps of $\mathrm{AF}$ are required. The second step, an in-bottle fermentation of a base wine with sugar, is followed by an ageing period in which the wine is in contact with dead yeast cells (Kemp et al., 2015). There are several factors that affect the final organoleptic quality, such as grape variety, vineyard management, quality of the base wine and the yeast strain inoculated in the second fermentation (Pozo-Bayón et al., 2010; Pérez-Magariño et al., 2015; Garofalo et al., 2016b). However, the evolution of the second fermentation and the ageing of the wine are of particular importance because they enhance the organoleptic properties of the base wine, giving the sparkling wine its characteristic aroma and flavour, foam ability and roundness. During the ageing process, which takes from several months to several years, the dead yeasts undergo autolysis and release their cell components into the wine (Pozo-Bayón et al., 2010; Kemp et al., 2015; MartínezLapuente et al., 2015; Velázquez et al., 2016). Recent studies have been focused on using a combination of killer yeasts to accelerate this autolysis and reduce the maturing time (Velázquez et al., 2016). Such investigations have demonstrated that killer and sensitive yeasts in co-culture can accelerate the onset of autolysis under oenological conditions, thus producing a positive effect on the aroma and flavour of sparkling wine. Non-Saccharomyces yeast species are not used in the secondary fermentation of sparkling wines, possibly because of their low tolerance of the ethanol content and the possible increase in glycerol content, which could affect the flavour, mouthfeel and viscosity of the final product (Fleet, 2008; Kemp et al., 2015).

\section{Malolactic starter cultures}

While AF is essential for the conversion of musts into wine, MLF causes an increase in wine $\mathrm{pH}$ and a decrease in titratable acidity, leading to a decrease in wine sourness and an increase in microbial stability (Bartowsky, 2009; Lerm et al., 2010). Among all LAB species, Oenococcus oeni is probably the best adapted to resist wine conditions (Bauer \& Dicks, 2004; Betteridge et al., 2015). During MLF, the metabolism of $O$. oeni can improve the organoleptic properties of wine by producing various secondary metabolites (Bartowsky, 2005; Bartowsky \& Borneman, 2011). MLF can be controlled by inoculating commercial starters; nevertheless, the induction of MLF by O. oeni commercial starters is not always successful because wine is a very harsh environment (Ruiz et al., 2010). As in the AF, the employment of autochthonous starter cultures that are well adapted to the conditions of a specific wine-producing area has been suggested (Ruiz et al., 2010), and several studies have been performed on the characterization of $O$. oeni biodiversity (Capozzi et al., 2010b; Bordas et al., 2013; González-Arenzana et al., 2013; Garofalo et al., 2015; Berbegal et al., 2017). Furthermore, several investigations are focused on alternative LAB such as Lactobacillus plantarum to perform the MLF in wine (Berbegal et al., 2016; Iorizzo et al., 2016; Lucio et al., 2016). Lactobacillus spp. can survive under winemaking conditions and possess many favourable biological properties that would make them a suitable candidate for MLF starter cultures (Du Toit et al., 2011). In fact, during the fermentation process they are also able to carry out a number of secondary metabolic reactions of great importance for aroma and flavour in wines (Liu, 2002; Matthews et al., 2004). They also exhibit a wider range and greater spectrum of enzymatic activities than $O$. oeni, and can contribute to a greater modification of wine aroma. Several authors have demonstrated that many wine-associated lactobacilli contain genes encoding important enzymes that are active under winemaking conditions (Du Toit et al., 2011; Lerm et al., 2011). Besides, the use of L. plantarum has been suggested as a biological acidification method because of its ability to produce high concentrations of lactic acid (Onetto \& Bordeu, 2015; Lucio et al., 2016). Just as in the case with $O$. oeni, the employment of autochthonous L. plantarum strains that are well adapted to the conditions of a specific wine-producing area has been suggested (Bravo-Ferrada et al., 2013; Berbegal et al., 2016).

\section{Safety improvement: the importance of biocontrol}

The success in terms of the safety and quality of winemaking depends mainly on the metabolism of microorganisms associated with grapes and with the fermentation process (Cocolin et al., 2001; Spano et al., 2010). Indeed, several microorganisms can cause depreciation of wine since they produce undesirable compounds that negatively affect wine aroma and flavours (e.g. volatile phenols) and/or are toxic to humans, such as biogenic amines (BA) or mycotoxins (Russo et al., 2016).

\section{Brettanomyces bruxellensis}

Among others, the yeast Brettanomyces bruxellensis is generally considered one of the main oenological spoilage microbes, since it is able to survive during the winemaking process and confers off-odours to wine (Di Toro et al., 2015; Steensels et al., 2015; Capozzi et al., 2016a). Different $B$. bruxellensis strains can produce several compounds that are detrimental to the organoleptic quality of wine, including some classes of volatile phenols that derive from the sequential conversion of specific hydroxycinnamic acids such as ferulate and p-coumarate. Hydroxycinnamate decarboxylase first transforms these hydroxycinnamic acids into vinylphenols, which are then reduced to 4-ethylphenol and 4-ethylguaiacol respectively by the vinylphenol 
reductase (Di Toro et al., 2015). Elevated concentrations of 4-ethylphenol are associated with unpleasant aromas described as "stable", "horse sweat" or "leather" (Steensels et al., 2015). To control the proliferation of this yeast, sulphur dioxide is commonly employed, but the efficiency of this chemical compound is subject to wine composition and it can also elicit allergic reactions in humans. Biological alternatives, such as the use of starter cultures as biocontrol agents (García-Moruno \& Muñoz, 2012; Oro et al., 2014), are therefore actively sought.

Current studies are focused on identifying and characterising yeast species able to synthesise killer toxins, i.e. antimicrobial compounds able to inhibit the growth of $B$. bruxellensis in wine. Mehlomakulu and co-workers (2014) identified two killer toxins, CpKT1 and CpKT2, from the wine-isolated yeast Candida pyralidae. The two proteins exhibited killer activity against several $B$. bruxellensis strains, especially in grape juice. These killer toxins inhibited neither the $S$. cerevisiae nor the LAB strains tested. A similar action against the above spoilage yeast was described for the killer toxins isolated from $T$. delbrueckii (Villalba et al., 2016) and from Ustilago maydis (Santos et al., 2011). These killer toxins were both active under oenological conditions, confirming their potential use as a biocontrol tool in the winemaking and wine ageing process.

\section{Biogenic amines and mycotoxins}

Histamine is the most widely studied amine due to its ability to produce headaches, hypotension and digestive problems when ingested with food (Ladero et al., 2010). The main microorganisms responsible for histamine production in wine are LAB, especially Lactobacillus hilgardii, L. mali, O. oeni and Pediococcus parvulus (Landete et al., 2007; Coton et al., 2010). Moreover, several strains of Enterococcus spp. and Staphylococcus spp. have recently been isolated from must and wine and described as histamine producers (Capozzi et al., 2010a; García-Moruno \& Muñoz, 2012; BenaventGil et al., 2016). Tristezza and collaborators (2013) have demonstrated that some non-Saccharomyces yeasts of wine origin also are able to produce BA. These findings further underline the importance of selecting oenological starters lacking the genetic determinants to produce BA (Landete et al., 2007; Capozzi et al., 2014). The addition of sulphite and the inoculation of starter cultures are common practices in winemaking in order to inhibit the growth of unknown and indigenous microorganisms. Indeed, the co-inoculation of yeast and LAB has been proposed as an interesting practice to better control the BA-producing microorganisms (Izquierdo-Cañas et al., 2012; Smit et al., 2012). However, preventing the biosynthesis of BA in wine is not always possible, as a number of microbiological, chemical and physical conditions could affect the organoleptic properties of the wine, or result in incompatibility with specific production processes, such as for organic or $\mathrm{SO}_{2}$-free wines. An alternative to the prevention strategy could be to rely on the use of BA-degrading microorganisms (Mohedano et al., 2015). Some wine LAB strains belonging to Lactobacillus and Pediococcus species were demonstrated to be capable of degrading histamine, tyramine and putrescine (García-Ruiz et al., 2011; Capozzi et al., 2012). These strains showed promising technological properties, suggesting that the ability to degrade BA could also be a criterion to select a new generation of starter cultures (Capozzi et al., 2012). Recently, Callejoen and co-workers (2014) have shown that two enzymes isolated and purified from L. plantarum J16 and P. acidilactici CECT 5930 strains, and identified as multicopper oxidases, were able to degrade histamine, tyramine and putrescine, relevant BAs in wine (Beneduce et al., 2010). Such a finding opens a new perspective on the possibility of employing purified microbial enzymes to deal with the problem of high amine concentrations in wine (Callejón et al., 2016).

In the last few years there have been several studies on the presence of mycotoxins in wine, mainly ochratoxin A (OTA), prompted by the awareness of their negative effects on health (Russo et al., 2016). OTA is produced by Aspergillus spp. and Penicillium spp. and derives from 3,4-dihydrocumarin linked to an amide bond with an amino group of L-b-phenylalanine. This mycotoxin is an important threat to humans because it accumulates in several tissues within the body and is classified by the International Agency for Research on Cancer [IARC] (1993) in the group 2B as a possible human carcinogen. Many physical, chemical and biological approaches to perform the decontamination of OTA have been investigated, but only a few methodologies are practicable at the industrial level (Quintela et al., 2012). A promising method for wine decontamination could be bioremediation through toxin degradation or adsorption (Quintela et al., 2012). In the last few years, many different yeast/bacterial strains have been demonstrated to be able to hydrolyse OTA by the action of a putative peptidase, which degrades OTA into the less toxic OT $\alpha$ (De Bellis et al., 2015; Petruzzi et al., 2017b).

Finally, considering the importance of assuring the safety of starter cultures in order to exert correct biocontrol, it is important to underline that the increasing number of complete genome sequences of wine-related microorganisms (Bartowsky \& Borneman, 2011; Lamontanara et al., 2014; 2015; Campbell-Sills et al., 2015) represents a considerable tool to assess the safety traits of industrial strains (Salvetti et al., 2016).

\section{Functional quality: microbial influence on functional properties}

The principal compounds related to the benefits ascribed to wine consumption are the polyphenols. These substances have a potentially positive effect on human health due to their antioxidant and free radical scavenging properties (Liang et al., 2014), thus endowing red wine with the "functional properties" that can help to prevent a number of human illnesses (Giovinazzo \& Grieco, 2015). Among all polyphenols present in grapes and wine, resveratrol is thought to be one of the principal agents with healthpromoting effects (Garcia-Alonso et al., 2009; Kundu \& Surh, 2008).

Polyphenols are present mainly in the seeds and skin of grape berries, thereby they are extracted during the winemaking process. However, their final concentration in wine depends on the efficiency of the contact of the liquid must with the solid parts of the grape bunches, as well as 
on the grape variety. The relationship between the ripening stages of the grape at harvest time and the polyphenol content in wine has been studied thoroughly (Castillo-Muñoz et al., 2010). Factors such as the microbiological, chemical and physical properties of raw materials have been demonstrated to be able to further modify the structure and concentration of polyphenols during the fermentation, fining and storage of wine (Giovinazzo \& Grieco, 2015).

The potential correlation between the use of specific yeast starter cultures and the polyphenol content and antioxidant capacity of wine has been investigated in great depth (Mulero et al., 2011; Rodriguez-Nogales et al., 2012; Tufariello et al., 2014). Recently, Rodriguez-Nogales and co-workers (2012) demonstrated that the addition of $\beta$-glucanases and other yeast-derived oenological additives enhanced the antioxidant capacity of sparkling wines. Tufariello et al. (2014) provided evidence of a relationship between the yeast culture used in the winemaking process and the chemical profile of the wine, highlighting that the strain-specific properties of a yeast are able to change the colour and the aromatic profile of the final wine. A largescale analysis was carried out by analysing the effects of 19 different $S$. cerevisiae starter strains on the total polyphenol content and the antioxidant capacity of the resultant wines (Brandolini et al., 2007). The authors showed that the two parameters were different in each of the obtained wines, thus indicating that polyphenol extraction during vinification is a yeast strain-dependent feature. During AF, different yeast strains were able to modify the trans-resveratrol concentration and antioxidant activities of the final products. Caridi et al. (2015; 2017) studied the capacity of $S$. cerevisiae strains to modulate the level of antioxidant compounds in wines and the inheritability of this yeast trait, demonstrating the relevance of wine yeast selection to improve the content of the antioxidant phenolic compounds in red wine.

Other than the impact on polyphenols, it is crucial to remember that several metabolites released by wine yeasts during AF might influence human health (e.g. melatonin production (Fernández-Cruz et al., 2017).

Several functional properties can also be ascribed to LAB resources used/associated with malolactic fermentation. In particular, probiotics and immunomodulatory properties have been reported for wine LAB strains (Foligné et al., 2010; García-Ruíz et al., 2014), while antioxidant properties have been attributed to $O$. oeni strains ( $\mathrm{Su}$ et al., 2015). Nevertheless, additional studies are required in order to improve technological approaches for increasing the enrichment of the wine with "functional properties" during the winemaking process and contributing to the functional quality of the final wine.

\section{PROCESS INNOVATION}

\section{Cost and time reduction}

\section{Yeast and lactic acid bacteria co-inoculation}

The early inoculation of a LAB starter together with yeast directly into the must has been suggested to i) simultaneously promote $\mathrm{AF}$ and MLF; ii) overcome the problems of sluggish or stuck MLF, usually caused by the high ethanol content, low $\mathrm{pH}$ and nutrient depletion of wines; iii) reduce the time and costs of wine production; and iv) enhance the quality and safety of wine. However, in spite of its many advantages in the winemaking process, the co-inoculation approach and, particularly, the unpredictable interactions between specific $S$. cerevisiae and LAB strains during grape must fermentation, should be considered carefully (Alexandre et al., 2004; Mendoza et al., 2010). Recent studies have been performed by co-inoculating yeasts with commercial LAB strains in red grape must (Abrahamse et al., 2012; Muñoz et al., 2014; Tristezza et al., 2016a). Muñoz and collaborators (2014) investigated the inoculation of one commercial $O$. oeni strain with two $S$. cerevisiae strains either simultaneously, three days after the yeast inoculation, or when AF was close to its end. Early bacterial inoculations with each yeast strain allowed for the rapid development of the bacterial populations, with the length of MLF reduced to six days. Abrahamse and Bartowsky (2012) and Tristezza et al. (2016a) evaluated the interactions between commercial yeast and $O$. oeni strains. Their results indicated that simultaneous yeast/bacteria inoculation at the beginning of vinification reduced the duration of the process and simultaneously lowered volatile acidity. Furthermore, compatibility specifications between commercial yeasts and LAB strains were observed, suggesting the importance of the assessment of microbial compatibility before their utilisation in large-scale vinification. Similar results were obtained when autochthonous $O$. oeni strains were co-inoculated with S. cerevisiae (Izquierdo-Cañas et al., 2012; Cañas et al., 2015). The concurrent yeast/bacteria inoculation of Cabernet Franc, Tempranillo and Merlot musts produced a significant reduction in the duration of the process, without an increase in volatile acidity. In addition, the BA content was also lower in wines produced by co-inoculation. This co-inoculation approach has also been proven to be successful using autochthonous L. plantarum strains (Berbegal et al., 2016; Iorizzo et al., 2016). The co-inoculation of $S$. cerevisiae and L. plantarum in grape must improved the bacterial adaptation to the harsh conditions of wine, completing the MLF and reducing the total fermentation time.

\section{Immobilisation of yeast and lactic acid bacteria}

In the last years, increasing attention has been paid to using immobilised cells for fermentation processes, such as in still wine, sparkling wine and cider production (e.g. Bleve et al., 2016). This is mainly due to the numerous advantages that cell immobilisation offers, including enhanced fermentation productivity, feasibility of continuous processing, avoidance of microbial contamination, starter cell stability and recycling (García-Martínez et al., 2015). Four basic types of yeast cell immobilisation are classified by the mechanism of cell localisation and the nature of the support material. The two simplest mechanisms involve immobilisation on a support surface or flocculation. The third type of immobilisation is a mechanical containment behind a barrier. Finally, the most investigated type in the last few decades has been the entrapment in a porous matrix (Nedović et al., 2015). Many different carriers have been proposed for the immobilisation of yeasts and bacteria for wine making, including inorganic and organic materials, mainly polysaccharides, and natural products such as cellulosic materials, cereal grains and pieces of fruit (e.g. Servetas et al., 2013; Bleve et al., 2016). 
With reference to yeast immobilisation, the use of corn grains (Kandylis et al., 2012) as supports for $S$. cerevisiae immobilisation was found to be efficient during both ambient and low-temperature fermentation processes. These systems showed good operational stability during repeated batch fermentations of grape must, even at extremely low temperatures. In other recent studies, the cells of $S$. cerevisiae were entrapped in biocapsules, with walls composed of the mycelium of the fungus Penicillium chrysogenum. The immobilisation was found to be advantageous for sweet wine production via partial fermentation of raisin must, by overcoming the process limitation related to the growth and fermentation difficulties of yeast cells under osmotic stress (López de Lerma et al., 2012; García-Martínez et al., 2013). Vilela et al. (2013) used cells of $S$. cerevisiae, immobilised in double-layer alginate-chitosan beads, for the deacidification of white wine with high volatile acidity. The immobilised cells caused a rapid decrease in volatility without affecting the ethanol concentration considerably. It further demonstrated the possibility of extended storage of thermally dried immobilised yeast in different supports, such as delignified brewer's spent grains, freeze-dried wheat, gluten pellets and delignified cellulosic material (Tsaousi et al., 2010), without any loss of cell viability and fermentation activity. The produced wines had similar organoleptic properties to those of wines fermented with free cell cultures, and this highlights the commercial potential of immobilised yeast starters for industrial application, also in terms of cost reduction (Nedović et al., 2015).

Lactic acid bacteria have also been immobilised with positive results. Genisheva et al. (2013) evaluated the efficiency of immobilised $O$. oeni on corncobs, grape skins and grape stems for the implementation of MLF in white wine. This study showed the protection of immobilised cells against the inhibitory effect of ethanol and $\mathrm{SO}_{2}$. Furthermore, the coimmobilisation of $S$. cerevisiae and $O$. oeni, on wheat starch gel and tubular delignified cellulosic material respectively, was evaluated for simultaneous AF and MLF (Servetas et al., 2013). The biocatalyst was effective for simultaneous, low-temperature $\left(10^{\circ} \mathrm{C}\right)$ wine fermentations. Bleve et al. (2016) carried out the simultaneous immobilisation of $S$. cerevisiae and $O$. oen $i$ in alginate beads and used them in microvinification tests to produce Negroamaro wine. Co-immobilisation of $S$. cerevisiae and $O$. oeni allowed an efficient fermentation process to be performed, producing low levels of volatile acidity and ethanol and glycerol concentrations, comparable with those obtained by cell sequential inoculum and co-inoculum of yeast and bacteria cells in free form. More importantly, the co-immobilisation strategy produced a significant decrease in the time needed to complete AF and MLF.

As described above, several studies have provided evidence that yeasts and LAB immobilised on suitable supports can be used to improve the organoleptic properties of wines (Nedović et al., 2015). The long-term storage of immobilised cells, as well as scaled-up processes, could promote the industrialisation of immobilised technology in winemaking.
Microbial resources for the valorisation of wine industry waste

The wine industry produces a considerable quantity of organic waste that is both highly polluting and expensive to dispose. These residues are mainly composed of rich nutrients such as sugars and cellulose that are both biodegradable and proper substrates for biotechnological production (Pérez-Bibbins et al., 2015). Even though the release of the waste produced in the wine industry is a relevant environmental problem because of its chemical nature, the rich composition of the above residue provides an opportunity to turn it into precious secondary products (Jin \& Kelly, 2009). Recent investigations have developed new methods for the management of wine industry wastes and for their biotechnological employment through the application of molecular and classical microbiological approaches. Among these, different microorganisms have been used in several different treatments, either to i) clean up the waste by eliminating toxic compounds, ii) synthesise expensive molecules such as enzymes and organic acids, or iii) produce microbial biomass for use in animal breeding. Moreover, recent developments in "omics" approaches have opened up new horizons for the genetic and metabolic engineering of microorganisms in order to get new, attractive biotechnological products (Hivrale et al., 2015).

Indeed, the unprocessed lees may be used alone or in combination with corn steep liquor to prepare fermentative media for the biotechnological production of several compounds, such as lactic acid or xylitol (Salgado et al., 2010). The use of vinasse (i.e. the wastewater produced in the distillery, essentially from wine lees and grape marc) has also been proposed for the production of fungal biomass for aquaculture (Nitayavardhana \& Khanal, 2010) and as a substrate for yeast-directed fermentation to obtain protein extracts (Silva et al., 2011). Several investigations have indicated the possible application of vinasse as a "green" antifungal compound, since it has been demonstrated to directly inhibit the growth of Fusarium oxysporum, even at low concentrations (from 5\% to 7\%) (Santos et al., 2008; Bai et al., 2008).

The vine shoots obtained after the seasonal trimmings are usually reduced to ashes directly in the field, thus freeing toxic compounds and greenhouse gases. In order to avoid these problems, the trimmed vine shoots have been suggested as a source of hemicellulosic sugars to be biotechnologically converted into different valuable products (Devesa-Rey et al., 2011), such as lactic acid and biosurfactants, after their fermentation by L. pentosus (Alonso et al., 2009). Grape marc, the most abundant and valueless winery waste, is a composite lingo-cellulosic material. Even though it is usually directed to the distillery for ethanol production, the huge quantity of distilled grape marc is not proficiently utilised at the end of the winemaking process. In fact, grape marc contains a large amount of hemicellulosic sugars, which can be used to produce i) lactic acid and bioemulsifiers by L. pentosus fermentations (Portilla et al., 2010); ii) antiallergic compounds after Lactobacillus spp. fermentation (Tominaga et al., 2010); and iii) hydrolytic enzymes by solid state fermentation (Díaz et al., 2011).

Thus, there may be biotechnological alternatives to the 
costly treatments actually used to process the vast amounts of waste produced by the wine industry. It is interesting to underline how the application of pro-environmental business practices and environmentally sustainable approaches may also promote the profile of a brand and improve its image, obtaining tangible benefits as well as better consumer acceptance.

\section{CONCLUSIONS}

The management of microbial resources has come to play an important role in the innovation of the oenological sector. This paper provides empirical evidence of recent developments in the application of microbial resources for product innovation, centred on the sensorial, safety and functional quality of wine, and for processes focused on the reduction of costs and of the environmental impact of winemaking processes. Starter cultures will be of crucial value for this industry in the near future. Solutions may include autochthonous microorganisms selected to support the "terroir" dimension and to offer biotechnological solutions to cope with specific local oenological issues, multi-strain starters to improve organoleptic properties and strains for biocontrol, avoiding contamination and reducing the inputs to the winemaking process. Nevertheless, further studies in this field are needed, since consumers and wineries will benefit from more accurate knowledge about microbial resources and wine.

\section{LITERATURE CITED}

Abrahamse, C.E. \& Bartowsky, E.J., 2012. Timing of malolactic fermentation inoculation in Shiraz grape must and wine: Influence on chemical composition. World J. Microbiol. Biotechnol. 28, 255-265.

Alexandre, H., Costello, P.J., Remize, F., Guzzo, J. \& Guilloux-Benatier, M., 2004. Saccharomyces cerevisiae-Oenococcus oeni interactions in wine: Current knowledge and perspectives. Int. J. Food Microbiol. 93, 141-154.

Alonso, A., Belda, I., Santos, A., Navascués, E. \& Marquina, D., 2015. Advances in the control of the spoilage caused by Zygosaccharomyces species on sweet wines and concentrated grape musts. Food Control 51, $129-134$.

Alonso, J.L., Garrote, G., Domínguez, H., Santos, V. \& Parajó, J.C., 2009. Lactic acid from apple pomace. A laboratory experiment for teaching valorisation of wastes. CyTA - J. Food 7(2), 83-88.

Bagder Elmaci, S., Gulgor, G., Tokatli, M., Erten, H., Isci, A. \& Ozcelik, F., 2015. Effectiveness of chitosan against wine-related microorganisms. Antonie v. Leeuwenh. 107, 675-686.

Bai, Z., Jin, B., Li, Y., Chen, J. \& Li, Z., 2008. Utilization of winery wastes for Trichoderma viride biocontrol agent production by solid state fermentation. J. Environ. Sci. 20, 353-358.

Balboa-Lagunero, T., Arroyo, T., Cabellos, J.M. \& Aznar, M., 2013. Yeast selection as a tool for reducing key oxidation notes in organic wines. Food Res. Int. 53, 252-259.

Bartowsky, E.J., 2005. Oenococcus oeni and malolactic fermentation moving into the molecular arena. Aust. J. Grape Wine Res. 11, 174-187.

Bartowsky, E.J., 2009. Bacterial spoilage of wine and approaches to minimize it. Lett. Appl. Microbiol. 48, 149-156.

Bartowsky, E. \& Borneman, A., 2011. Genomic variations of Oenococcus oeni strains and the potential to impact on malolactic fermentation and aroma compounds in wine. Appl. Microbiol. Biotechnol. 92, 441-447.
Bauer, R. \& Dicks, L.M.T., 2004. Control of malolactic fermentation in wine. A review. S. Afr. J. Enol. Vitic. 25, 74-88.

Belda, I., Conchillo, L.B., Ruiz, J., Navascués, E., Marquina, D. \& Santos, A., 2016. Selection and use of pectinolytic yeasts for improving clarification and phenolic extraction in winemaking. Int. J. Food Microbiol. 223, 1-8.

Belda, I., Ruiz, J., Esteban-Fernandez, A., Navascues, E., Marquina, D., Santos, A. \& Moreno-Arribas, M.V., 2017. Microbial contribution to wine aroma and its intended use for wine quality improvement. Molecules 22(2), 189.

Bely, M., Stoeckle, P., Masneuf-Pomarède, I. \& Dubourdieu, D., 2008. Impact of mixed Torulaspora delbrueckii-Saccharomyces cerevisiae culture on high-sugar fermentation. Int. J. Food Microbiol. 122, 312-320.

Benavent-Gil, Y., Berbegal, C., Lucio, O., Pardo, I. \& Ferrer, S., 2016. A new fear in wine: Isolation of Staphylococcus epidermidis histamine producer. Food Control 62, 142-149.

Beneduce, L., Romano, A., Capozzi, V., Lucas, P., Barnavon, L., Bach, B., Vuchot, P., Grieco, F. \& Spano, G., 2010. Biogenic amine in wines. Ann. Microbiol. 60, 573-578.

Berbegal, C., Benavent-Gil, Y., Navascués, E., Calvo, A., Albors, C., Pardo, I. \& Ferrer, S., 2017. Lowering histamine formation in a red Ribera del Duero wine (Spain) by using an indigenous O. oeni strain as a malolactic starter. Int. J. Food Microbiol. 244, 11-18.

Berbegal, C., Peña, N., Russo, P., Grieco, F., Pardo, I., Ferrer, S., Spano, G. \& Capozzi, V., 2016. Technological properties of Lactobacillus plantarum strains isolated from grape must fermentation. Food Microbiol. 57, 187-194.

Betteridge, A., Grbin, P. \& Jiranek, V., 2015. Improving Oenococcus oeni to overcome challenges of wine malolactic fermentation. Trends Biotechnol. $33,547-553$.

Bleve, G., Tufariello, M., Vetrano, C., Mita G. \& Grieco F., 2016. Simultaneous alcoholic and malolactic fermentations by Saccharomyces cerevisiae and Oenococcus oeni cells co-immobilized in alginate beads. Front. Microbiol. 14(7), 943.

Bordas, M., Araque, I., Alegret, J.O, El Khoury, M., Lucas, P., Rozès, N., Reguant, C. \& Bordons, A., 2013. Isolation, selection, and characterization of highly ethanol-tolerant strains of Oenococcus oeni from south Catalonia. Int. Microbiol. 16, 113-123.

Brandolini, V., Fiore, C., Maietti, A., Tedeschi, P. \& Romano, P., 2007. Influence of Saccharomyces cerevisiae strains on wine total antioxidant capacity evaluated by photochemiluminescence. World J. Microbiol. Biotechnol. 23, 581-586.

Bravo-Ferrada, B.M., Hollmann, A., Delfederico, L., Valdés la Hens, D., Caballero, A. \& Semorile, L., 2013. Patagonian red wines: Selection of Lactobacillus plantarum isolates as potential starter cultures for malolactic fermentation. World J. Microbiol. Biotechnol. 29, 1-13.

Callejón, S., Sendra, R., Ferrer, S. \& Pardo, I., 2014. Identification of a novel enzymatic activity from lactic acid bacteria able to degrade biogenic amines in wine. Appl. Microbiol. Biotechnol. 98, 185-198.

Callejón, S., Sendra, R., Ferrer, S. \& Pardo, I., 2016. Cloning and characterization of a new laccase from Lactobacillus plantarum J16 CECT 8944 catalyzing biogenic amines degradation. Appl. Microbiol. Biotechnol. 100, 3113-3124.

Campbell-Sills, H., Capozzi, V., Romano, A., Cappellin, L., Spano, G., Breniaux, M., Lucas, P. \& Biasioli, F., 2016. Advances in wine analysis by PTR-ToF-MS: Optimization of the method and discrimination of wines from different geographical origins and fermented with different malolactic starters. Int. J. Mass Spectrom. 397/398, 42-51. 
Campbell-Sills, H., El Khoury, M., Favier, M., Romano, A., Biasioli, F., Spano, G., Sherman, D.J., Bouchez, O., Coton, E., Coton, M., Okada, S., Tanaka, N., Dols-Lafargue, M. \& Lucas, P.M. 2015. Phylogenomic analysis of Oenococcus oeni reveals specific domestication of strains to cider and wines. Genome Biol. Evol. 7, 1506-1518.

Cañas, P.M., Romero, E.G., Perez-Martin, F., Sesena, S. \& Palop, M.L., 2015. Sequential inoculation versus co-inoculation in Cabernet Franc wine fermentation. Food Sci. Technol. Int. 21, 203-212.

Capozzi, V. \& Spano, G., 2011. Food microbial biodiversity and "microbes of protected origin". Front. Microbiol. 2, 237.

Capozzi, V., Di Toro, M.R., Grieco, F., Michelotti, V., Salma, M., Lamontanara, A., Russo, P., Orrù, L., Alexandre, H. \& Spano, G., 2016 a Viable but not culturable (VBNC) state of Brettanomyces bruxellensis in wine: New insights on molecular basis of VBNC behaviour using a transcriptomic approach. Food Microbiol. 59, 196-204.

Capozzi, V., Garofalo, C., Chiriatti, M.A., Grieco, F. \& Spano, G., 2015. Microbial terroir and food innovation: The case of yeast biodiversity in wine. Microbiol. Res. 181, 75-83.

Capozzi, V., Ladero, V., Beneduce, L., Fernádez, M., Alvarez, M.A., Benoit, B., Laurent, B., Grieco, F. \& Spano, G., 2010a. Isolation and characterization of tyramine-producing Enterococcus faecium strains from red wine. Food Microbiol. 28, 434-439.

Capozzi, V., Makhoul, S., Aprea, E., Romano, A., Cappellin, L., Sanchez Jimena, A., Spano, G., Gasperi, F., Scampicchio, M. \& Biasioli, F., 2016b. PTR-MS characterization of VOCs associated with commercial aromatic bakery yeasts of wine and beer origin. Molecules 21, 483.

Capozzi, V., Russo, P., Beneduce, L., Weidmann, S., Grieco, F., Guzzo, J. \& Spano, G., 2010b. Technological properties of Oenococcus oeni strains isolated from typical southern Italian wines. Lett. Appl. Microbiol. 50,327334.

Capozzi, V., Russo, P., Ladero, V., Fernández, M., Fiocco, D., Alvarez, M.A., Grieco, F. \& Spano, G., 2012. Biogenic amines degradation by Lactobacillus plantarum: Toward a potential application in wine. Front Microbiol. 3, 122.

Capozzi, V., Russo, P., Lamontanara, A., Orrù, L., Cattivelli, L. \& Spano, G., 2014. Genome sequences of five Oenococcus oeni strains isolated from Nero di Troia wine from the same terroir in Apulia, Southern Italy. Genome Announc. 2(5), e01077-01014.

Caridi, A., Sidari, R., Giuffrè, A.M., Pellicanò, T.M., Sicari, V., Zappia, C \& Poiana, M., 2017. Test of four generations of Saccharomyces cerevisiae concerning their effect on antioxidant phenolic compounds in wine. Eur. Food Res. Technol. 243, 1287-1294.

Caridi, A., Sidari, R., Kraková, L., Kuchta, T. \& Pangallo, D., 2015. Assessment of color adsorption by yeast using grape skin agar and impact on red wine color. OENO One 49, 195-203

Castillo-Muñoz, N., Gómez-Alonso, S., García-Romero, E. \& HermosínGutiérrez, I., 2010. Flavonol profiles of Vitis vinifera white grape cultivars. J. Food Comp. Anal. 23, 699-705.

Ciani, M. \& Comitini, F., 2015. Yeast interactions in multi-starter wine fermentation. Curr. Opin. Food Sci. 1, 1-6.

Ciani, M., Capece, A., Comitini, F., Canonico, L., Siesto, G. \& Romano, P. 2016. Yeast interactions in inoculated wine fermentation. Front. Microbiol. 7,555 .

Cocolin, L., Heisey, A. \& Mills, D.A., 2001. Direct identification of the indigenous yeasts in commercial wine fermentations. Am. J. Enol. Vitic. $52,49-53$.
Comitini, F., Gobbi, M., Domizio, P., Romani, C., Lencioni, L., Mannazzu, I. \& Ciani, M., 2011. Selected non-Saccharomyces wine yeasts in controlled multistarter fermentations with Saccharomyces cerevisiae. Food Microbiol. $28,873-882$.

Coton, M., Romano, A., Spano, G., Ziegler, K., Vetrana, C., Desmarais, C., Lonvaud-Funel, A., Lucas, P. \& Coton, E., 2010. Occurrence of biogenic amine-forming lactic acid bacteria in wine and cider. Food Microbiol. 27 $1078-1085$.

De Bellis, P., Tristezza, M., Haidukowski, M., Fanelli, F., Sisto, A., Mulè, G. \& Grieco, F., 2015. Biodegradation of ochratoxin A by bacterial strains isolated from vineyard soils. Toxins 7, 5079-5093.

De Benedictis, M., Bleve, G., Grieco, F., Tristezza, M., Tufariello, M. \& Grieco F., 2011 An optimized procedure for the enological selection of nonSaccharomyces starter cultures. Antonie Leeuwenhoek 99(2), 189-200.

Devesa-Rey, R., Vecino, X., Varela-Alende, J.L., Barral, M.T., Cruz, J.M. \& Moldes, A.B., 2011. Valorization of winery waste vs. the costs of not recycling. Waste Manag. 31, 2327-2335.

Díaz, A.B., Bolívar, J., De Ong, I., Caro, I. \& Blandino, A., 2011 Applicability of enzymatic extracts obtained by solid state fermentation on grape marc and orange peels mixtures in must clarification. LWT - Food Sci. Technol. 44(4), 840-846.

Díez, L., Rojo-Bezares, B., Zarazaga, M., Rodríguez, J.M., Torres, C. \& Ruiz-Larrea, F., 2012. Antimicrobial activity of pediocin PA-1 against Oenococcus oeni and other wine bacteria. Food Microbiol. 31, 167-172.

Di Toro, M.R., Capozzi, V., Beneduce, L., Alexandre, H., Tristezza, M., Durante, M., Tufariello, M., Grieco, F. \& Spano, G., 2015. Intraspecific biodiversity and 'spoilage potential' of Brettanomyces bruxellensis in Apulian wines. LWT - Food Sci. Technol. 60, 102-108.

Du Toit, M., Engelbrecht, L., Lerm, E. \& Krieger-Weber, S., 2011. Lactobacillus: The next generation of malolactic fermentation starter cultures - An overview. Food Bioproc. Tech. 4, 876-906.

Fernández-Cruz, E., Alvarez-Fernandez, M.A., Valero, E., Troncoso, A.M. \& Garcia-Parrilla, M.C., 2017. Melatonin and derived 1-tryptophan metabolites produced during alcoholic fermentation by different wine yeast strains. Food Chem. 217, 431-437.

Fleet, G.H., 2008. Wine yeasts for the future. FEMS Yeast Res. 8, 979-995.

Francesca, N., Gaglio, R., Alfonzo, A., Settanni, L., Corona, O., Mazzei, P., Romano, R., Piccolo, A. \& Moschetti, G., 2016. The wine: Typicality or mere diversity? The effect of spontaneous fermentations and biotic factors on the characteristics of wine. Agric. Agric. Sci. Procedia 8, 769-773.

Foligné, B., Dewulf, J., Breton, J., Claisse, O., Lonvaud-Funel, A. \& Pot, B., 2010. Probiotic properties of non-conventional lactic acid bacteria: Immunomodulation by Oenococcus oeni. Int. J. Food Microbiol. 140, 136145 .

Garcia-Alonso, M., Minihane, A.-M., Rimbach, G., Rivas-Gonzalo, J.C. \& de Pascual-Teresa, S., 2009. Red wine anthocyanins are rapidly absorbed in humans and affect monocyte chemoattractant protein 1 levels and antioxidant capacity of plasma. J. Nutr. Biochem. 20, 521-529.

García-Martínez, T., De Lerma, N.L., Moreno, J., Peinado, R.A., Millán, M.C. \& Mauricio, J.C., 2013. Sweet wine production by two osmotolerant Saccharomyces cerevisiae strains. J. Food Sci. 78, 874-879.

García-Martínez, T., Moreno, J., Mauricio, J.C. \& Peinado, R., 2015. Natural sweet wine production by repeated use of yeast cells immobilized on Penicillium chrysogenum. LWT - Food Sci. Technol. 61, 503-509.

García-Moruno, E. \& Muñoz, R., 2012. Does Oenococcus oeni produce histamine? Int. J. Food Microbiol. 157, 121-129. 
García-Ruíz, A., González de Llano, D., Esteban-Fernández, A., Requena, T., Bartolomé, B. \& Moreno-Arribas, M.V., 2014. Assessment of probiotic properties in lactic acid bacteria isolated from wine. Food Microbiol. 44, $220-225$.

García-Ruíz, A., González-Rompinelli, E.M., Bartolomé, B. \& MorenoArribas, M.V., 2011. Potential of wine-associated lactic acid bacteria to degrade biogenic amines. Int. J. Food Microbiol. 148, 115-120.

Garofalo, C., Arena, M., Laddomada, B., Cappello, M., Bleve, G., Grieco, F., Beneduce, L., Berbegal, C., Spano, G. \& Capozzi, V., 2016a. Starter cultures for sparkling wine. Fermentation 2, 21.

Garofalo, C., El Khoury, M., Lucas, P., Bely, M., Russo, P., Spano, G. \& Capozzi, V., 2015. Autochthonous starter cultures and indigenous grape variety for regional wine production. J. Appl. Microbiol. 118, 1395-1408.

Garofalo, C., Tristezza, M., Grieco, F., Spano, G. \& Capozzi, V., $2016 b$. From grape berries to wine: Population dynamics of cultivable yeasts associated to "Nero di Troia" autochthonous grape cultivar. World J. Microbiol. Biotechnol. 32, 59.

Genisheva, Z., Mussatto, S.I., Oliveira, J.M. \& Teixeira, J.A., 2013. Malolactic fermentation of wines with immobilised lactic acid bacteria Influence of concentration, type of support material and storage conditions. Food Chem. 138, 1510-1514.

Gilbert, J.A., Van der Lelie, D. \& Zarraonaindia, I., 2014. Microbial terroir for wine grapes. Proc. Natl. Acad. Sci. U. S. A. 111,5-6.

Giovinazzo, G. \& Grieco, F., 2015. Functional properties of grape and wine polyphenols. Plant Foods Hum. Nutr. 70, 454-462.

González-Arenzana, L., Santamaría, P., López, R. \& López-Alfaro, I., 2013. Indigenous lactic acid bacteria communities in alcoholic and malolactic fermentations of Tempranillo wines elaborated in ten wineries of La Rioja (Spain). Food Res. Int. 50, 438-445.

Guerrero, R.F. \& Cantos-Villar, E., 2015. Demonstrating the efficiency of sulphur dioxide replacements in wine: A parameter review. Trends Food Sci. Technol. 42, 27-43.

Guzzon, R., Widmann, G., Settanni, L., Malacarne, M., Francesca, N. \& Larcher, R., 2011. Evolution of yeast populations during different biodynamic winemaking processes. S. Afr. J. Enol. Vitic. 32, 242-250.

Hivrale, A.U., Pawar, P.K., Rane, N.R. \& Govindwar, S.P., 2015. Application of genomics and proteomics in bioremediation. In: Rathoure, A.K. \& Dhatwalia V.K. (eds.). Toxicity and waste management using bioremediation. IGI Global, Hershey, USA. pp. $97-112$.

Iorizzo, M., Testa, B., Lombardi, S.J., García-Ruiz, A., Muñoz-González, C., Bartolomé, B. \& Moreno-Arribas, M.V., 2016. Selection and technological potential of Lactobacillus plantarum bacteria suitable for wine malolactic fermentation and grape aroma release. LWT - Food Sci. Technol. 73, 557566 .

Izquierdo-Cañas, P.M., Pérez-Martín, F., Romero, E.G., Prieto, S.S. \& Herreros, M.d.1.L.P., 2012. Influence of inoculation time of an autochthonous selected malolactic bacterium on volatile and sensory profile of Tempranillo and Merlot wines. Int. J. Food Microbiol. 156, 245-254.

Jin, B. \& Kelly, J.M., 2009. Wine industry residues. In: Poonam, S.-N.N. $\&$ Ashok, P. (eds.). Biotechnology for agro-industrial residues utilisation. Springer, Dordrecht. pp. $293-311$

Jolly, N.P., Varela, C. \& Pretorius, I.S., 2014. Not your ordinary yeast: nonSaccharomyces yeasts in wine production uncovered. FEMS Yeast Res. 14, 215-237.

Kandylis, P., Mantzari, A., Koutinas, A.A. \& Kookos, I.K., 2012. Modelling of low temperature wine-making, using immobilized cells. Food Chem. $133,1341-1348$.
Kemp, B., Alexandre, H., Robillard, B. \& Marchal, R., 2015. Effect of production phase on bottle-fermented sparkling wine quality. J. Agric. Food Chem. 63, 19-38.

Kundu, J.K. \& Surh, Y.-J., 2008. Cancer chemopreventive and therapeutic potential of resveratrol: Mechanistic perspectives. Cancer Lett. 269, 243261 .

Ladero, V., Calles-Enriquez, M., Fernandez, M. \& Alvarez, M.A., 2010. Toxicological effects of dietary biogenic amines. Curr. Nutr. Food Sci. 6 , 145-156.

Lamontanara, A., Caggianiello, G., Orrù, L., Capozzi, V., Michelotti, V., Bayjanov, J.R., Renckens, B., Van Hijum, S.A., Cattivelli, L. \& Spano, G., 2015. Draft genome sequence of Lactobacillus plantarum Lp90 isolated from wine. Genome Announc. 3, e00097-e00015.

Lamontanara, A., Orrù, L., Cattivelli, L., Russo, P., Spano, G. \& Capozzi V., 2014. Genome sequence of Oenococcus oeni OM27, the first fully assembled genome of a strain isolated from an Italian wine. Genome Announc. 2, e00658-e00614.

Landete, J.M., Ferrer, S. \& Pardo, I., 2007. Biogenic amine production by lactic acid bacteria, acetic bacteria and yeast isolated from wine. Food Control 18, 1569-1574.

Lerm, E., Engelbrecht, L., \& Du Toit, M., 2010. Malolactic fermentation: The ABC's of MLF. S. Afr. J. Enol. Vitic. 31, 186-212.

Lerm, E., Engelbrecht, L. \& Toit, M.D., 2011. Selection and Characterisation of Oenococcus oeni and Lactobacillus plantarum South African Wine Isolates for Use as Malolactic Fermentation Starter Cultures. S. Afr. J. Enol. Vitic. 32,280-295.

Liang, Z., Cheng, L., Zhong, G.-Y. \& Liu, R.H., 2014. Antioxidant and antiproliferative activities of twenty-four Vitis vinifera grapes. PLoS One 9, e105146.

Liu, J., Warg, Q., Ma, H., Warg, S., 2010. Effect of pretreatment methods on L-lactic acid production from vinasse fermentation. Adv. Mater. Res. 113-116, 1302-1305.

Liu, P.T., Lu, L., Duan, C.Q. \& Yan, G.L., 2016. The contribution of indigenous non-Saccharomyces wine yeast to improved aromatic quality of Cabernet Sauvignon wines by spontaneous fermentation. LWT - Food Sci. Technol. 71, 356-363

Liu, S.Q., 2002. Malolactic fermentation in wine- Beyond deacidification. J. Appl. Microbiol. 92, 589-601.

Liu, Y., Rousseaux, S., Tourdot-Marechal, R., Sadoudi, M., Gougeon, R., Schmitt-Kopplin, P. \& Alexandre, H., 2017. Wine microbiome: A dynamic world of microbial interactions. Crit. Rev. Food Sci. Nutr. 57, 856-873.

López de Lerma, N., García-Martínez, T., Moreno, J., Mauricio, J.C. \& Peinado, R.A., 2012. Volatile composition of partially fermented wines elaborated from sun dried Pedro Ximénez grapes. Food Chem. 135, $2445-$ 2452 .

Lu, Y., Huang, D., Lee, P.R. \& Liu, S.Q., 2016. Assessment of volatile and non-volatile compounds in durian wines fermented with four commercial non-Saccharomyces yeasts. J. Sci. Food Agric. 96, 1511-1521.

Lucio, O., Pardo, I., Krieger-Weber, S., Heras, J.M. \& Ferrer, S., 2016. Selection of Lactobacillus strains to induce biological acidification in low acidity wines. LWT - Food Sci. Technol. 73, 334-341.

Martínez-Lapuente, L., Guadalupe, Z., Ayestarán, B. \& Pérez-Magariño, S., 2015. Role of major wine constituents in the foam properties of white and rosé sparkling wines. Food Chem. 174, 330-338.

Masneuf-Pomarede, I., Bely, M., Marullo, P. \& Albertin, W., 2015. The genetics of non-conventional wine yeasts: Current knowledge and future challenges. Front. Microbiol. 6, 1563. 
Matthews, A., Grimaldi, A., Walker, M., Bartowsky, E., Grbin, P. \& Jiranek, V., 2004. Lactic acid bacteria as a potential source of enzymes for use in vinification. Appl. Environ. Microbiol. 70, 5715-5731.

Medina, K., Boido, E., Dellacassa, E. \& Carrau, F., 2012. Growth of nonSaccharomyces yeasts affects nutrient availability for Saccharomyces cerevisiae during wine fermentation. Int. J. Food Microbiol. 157,245-250.

Mehlomakulu, N.N., Setati, M.E. \& Divol, B., 2014. Characterization of novel killer toxins secreted by wine-related non-Saccharomyces yeasts and their action on Brettanomyces spp. Int. J. Food Microbiol. 188, 83-91.

Mendoza, L.M., Manca de Nadra, M.C. \& Farías, M.E., 2010. Antagonistic interaction between yeasts and lactic acid bacteria of oenological relevance: Partial characterization of inhibitory compounds produced by yeasts. Food Res. Int. 43, 1990-1998.

Mohedano, M.L., López, P., Spano, G. \& Russo, P., 2015. Controlling the formation of biogenic amines in fermented foods. In: Holzapfel, W. (ed.). Advances in fermented foods and beverages. Woodhead Publishing, Cambridge, UK. pp. $273-310$.

Mulero, J., Zafrilla, P., Cayuela, J.M., Martínez-Cachá, A. \& Pardo, F., 2011. Antioxidant activity and phenolic compounds in organic red wine using different winemaking techniques. J. Food Sci. 76, C436-C440.

Muñoz, V., Beccaria, B. \& Abreo, E., 2014. Simultaneous and successive inoculations of yeasts and lactic acid bacteria on the fermentation of an unsulfited Tannat grape must. Braz. J. Microbiol. 45, 59-66.

Nedović, V., Gibson, B., Mantzouridou, T.F., Bugarski, B., Djordjevic, V., Kalusevic, A., Paraskevopoulou, A., Sandell, M., Smogrovicova, D. \& Yilmaztekin, M., 2015. Aroma formation by immobilized yeast cells in fermentation processes. Yeast 32, 173-216.

Nitayavardhana, S., Issarapayup, K., Pavasant, P. \& Khanal, S.K., 2013. Production of protein-rich fungal biomass in an airlift bioreactor using vinasse as substrate. Bioresour. Technol. 133, 301-306.

Onetto, C.A. \& Bordeu, E., 2015. Pre-alcoholic fermentation acidification of red grape must using Lactobacillus plantarum. Antonie v. Leeuwenh. $108,1469-1475$.

Oro, L., Ciani, M. \& Comitini, F., 2014. Antimicrobial activity of Metschnikowia pulcherrima on wine yeasts. J. Appl. Microbiol. 116, 12091217.

Pérez-Bibbins, B., Torrado-Agrasar, A., Salgado, J.M., Oliveira, R.P.d.S. \& Domínguez, J.M., 2015. Potential of lees from wine, beer and cider manufacturing as a source of economic nutrients: An overview. Waste Manag. 40, 72-81.

Pérez-Magariño, S., Ortega-Heras, M., Bueno-Herrera, M., MartínezLapuente, L., Guadalupe, Z. \& Ayestarán, B., 2015. Grape variety, aging on lees and aging in bottle after disgorging influence on volatile composition and foamability of sparkling wines. LWT - Food Sci. Technol. 61, 47-55.

Petruzzi, L., Capozzi, V., Berbegal, C., Corbo, M.R., Bevilacqua, A., Spano, G. \& Sinigaglia, M., 2017a. Microbial resources and enological significance: Opportunities and benefits. Front. Microbiol. 8, 995.

Petruzzi, L., Bevilacqua, A., Corbo, M.R., Speranza, B., Capozzi, V. \& Sinigaglia, M., 2017b. A focus on quality and safety traits of Saccharomyces cerevisiae isolated from Uva di Troia grape variety. J. Food. Sci. 82, 124133.

Portilla, O., Torrado, A.M., Domínguez, J.M. \& Moldes, A.B., 2010 Stabilization of kerosene/water emulsions using bioemulsifiers obtained by fermentation of hemicellulosic sugars with Lactobacillus pentosus. J. Agric. Food Chem. 58(18), 10162-10168.

Pozo-Bayón, M.A., Martín-Álvarez, P.J., Moreno-Arribas, M.V., AndujarOrtiz, I. \& Pueyo, E., 2010. Impact of using Trepat and Monastrell red grape varieties on the volatile and nitrogen composition during the manufacture of rosé Cava sparkling wines. LWT - Food Sci. Technol. 43, 1526-1532.
Provost, C. \& Pedneault, K., 2016. The organic vineyard as a balanced ecosystem: Improved organic grape management and impacts on wine quality. Sci. Hortic. 208,43-56.

Quintela, S., Villarán, M.C., De Armentia, I.L. \& Elejalde, E., 2012. Ochratoxin A removal from red wine by several oenological fining agents: Bentonite, egg albumin, allergen-free adsorbents, chitin and chitosan. Food Addit. Contam: Part A. 29, 1168-1174.

Rodriguez-Nogales, J.M., Fernández-Fernández, E., Gómez, M. \& VilaCrespo, J., 2012. Antioxidant properties of sparkling wines produced with $\beta$-glucanases and commercial yeast preparations. J. Food Sci. 77, C1005-C1010

Ruiz, P., Izquierdo, P.M., Seseña, S. \& Palop, M.L., 2010. Selection of autochthonous Oenococcus oeni strains according to their oenological properties and vinification results. Int. J. Food Microbiol. 137, 230-235.

Russo, P., Capozzi, V., Spano, G., Corbo, M.R., Sinigaglia, M. \& Bevilacqua, A., 2016. Metabolites of microbial origin with an impact on health: Ochratoxin A and biogenic amines. Front. Microbiol. 7, 482.

Sadoudi, M., Tourdot-Maréchal, R., Rousseaux, S., Steyer, D., GallardoChacón, J.-J., Ballester, J., Vichi, S., Guérin-Schneider, R., Caixach, J. \& Alexandre, H., 2012. Yeast-yeast interactions revealed by aromatic profile analysis of Sauvignon blanc wine fermented by single or co-culture of nonSaccharomyces and Saccharomyces yeasts. Food Microbiol. 32, 243-253.

Salgado, J.M., Rodríguez, N., Cortés, S. \& Domínguez, J.M., 2010. Improving downstream processes to recover tartaric acid, tartrate and nutrients from vinasses and formulation of inexpensive fermentative broths for xylitol production. J. Sci. Food Agr. 90, 2168-2177.

Salvetti, E., Orrù, L., Capozzi, V., Martina, A., Lamontanara, A., Keller, D., Cash, H., Felis, G.E., Cattivelli, L., Torriani, S. \& Spano, G. 2016. Integrate genome-based assessment of safety for probiotic strains: Bacillus coagulans GBI-30, 6086 as a case study. Appl. Microbiol. Biotechnol. 100, 4595-605.

Santos, A., Navascués, E., Bravo, E. \& Marquina, D., 2011. Ustilago maydis killer toxin as a new tool for the biocontrol of the wine spoilage yeast Brettanomyces bruxellensis. Int. J. Food Microbiol. 145, 147-154.

Santos, M., Diánez, F., De Cara, M. \& Tello, J.C., 2008. Possibilities of the use of vinasses in the control of fungi phytopathogens. Bioresour. Technol. 99, 9040-9043.

Santos, M.C., Nunes, C., Cappelle, J., Goncalves, F.J., Rodrigues, A., Saraiva, J.A. \& Coimbra, M.A., 2013. Effect of high pressure treatments on the physicochemical properties of a sulphur dioxide-free red wine. Food Chem. 141, 2558-2566.

Servetas, I., Berbegal, C., Camacho, N., Bekatorou, A., Ferrer, S., Nigam, P., Drouza, C. \& Koutinas, A.A., 2013. Saccharomyces cerevisiae and Oenococcus oeni immobilized in different layers of a cellulose/starch gel composite for simultaneous alcoholic and malolactic wine fermentations. Process Biochem. 48, 1279-1284.

Shekhawat, K., Bauer, F.F. \& Setati, M.E., 2017. Impact of oxygenation on the performance of three non-Saccharomyces yeasts in co-fermentation with Saccharomyces cerevisiae. Appl. Microbiol. Biotechnol. 101,2479-2491

Silva, C.F., Arcuri, S.L., Campos, C.R., Vileda, D.M., Alves, J.G.L.F. \& Schwan, R.F., 2011. Using the residue of spirit production a and bioethanol for protein production by yeast. Waste Manag. 31(1), 108-114.

Smit, A.Y., Engelbrecht, L. \& Du Toit, M., 2012. Managing your wine fermentation to reduce the risk of biogenic amine formation. Front Microbiol. 3, 76 .

Spano, G., Russo, P., Lonvaud-Funel, A., Lucas, P., Alexandre, H., Grandvalet, C., Coton, E., Coton, M., Barnavon, L., Bach, B., Rattray, F., Bunte, A., Magni, C., Ladero, V., Alvarez, M., Fernandez, M., Lopez, P., De Palencia, P.F., Corbi, A., Trip, H. \& Lolkema, J.S., 2010. Biogenic amines in fermented foods. Eur. J. Clin. Nutr. 64, S95-S100. 
Steensels, J., Daenen, L., Malcorps, P., Derdelinckx, G., Verachtert, H. \& Verstrepen, K.J., 2015. Brettanomyces yeasts - From spoilage organisms to valuable contributors to industrial fermentations. Int. J. of Food Microbiol. 206, 24-38.

Su, J., Wang, T., Li, Y.Y., Li, J., Zhang, Y., Wang, Y., Wang, H. \& Li, H., 2015. Antioxidant properties of wine lactic acid bacteria: Oenococcus oeni. Appl. Microbiol. Biotechnol. 99, 5189-5202.

Suzzi, G., Arfelli, G., Schirone, M., Corsetti, A., Perpetuini, G. \& Tofalo, R., 2012. Effect of grape indigenous Saccharomyces cerevisiae strains on Montepulciano d'Abruzzo red wine quality. Food Res. Int. 46, 22-29.

Tominaga, T., Kawaguchi, K., Kanesaka, M., Kawaguchi, H., Sirillo, E. \& Kamazawa, Y., 2010. Suppression of type-I-allergic responses by oral administration of grape marc fermented with Lactobacillus plantarum. Immunopharm. Immunot. 32(4), 593-599.

Tristezza, M., Di Feo, L., Tufariello, M., Grieco, F., Capozzi, V., Spano, G. \& Mita, G., 2016a. Simultaneous inoculation of yeasts and lactic acid bacteria: Effects on fermentation dynamics and chemical composition of Negroamaro wine. LWT - Food Sci. Technol. 66, 406-412.

Tristezza, M., Tufariello, M., Capozzi, V., Spano, G., Mita, G. \& Grieco, F., $2016 \mathrm{~b}$. The oenological potential of Hanseniaspora uvarum in simultaneous and sequential co-fermentation with Saccharomyces cerevisiae for industrial wine production. Front. Microbiol. 7, 670.

Tristezza, M., Vetrano, C., Bleve, G., Grieco, F., Tufariello, M., Quarta, A., Mita, G., Spano, G. \& Grieco F., 2012. Autochthonous fermentation starters for the industrial production of Negroamaro wines. J. Ind. Microbiol. Biotechnol. 39(1), 81-92.
Tristezza, M., Vetrano, C., Bleve, G., Spano, G., Capozzi, V., Logrieco, A., Mita, G. \& Grieco, F., 2013. Biodiversity and safety aspects of yeast strains characterized from vineyards and spontaneous fermentations in the Apulia Region, Italy. Food Microbiol. 36,335-342.

Tsaousi, K., Koutinas, A.A., Bekatorou, A. \& Loukatos, P., 2010. Fermentation efficiency of cells immobilized on delignified brewers' spent grains after low- and high-temperature thin layer thermal drying. Appl. Biochem. Biotechnol. 162, 594-606.

Tufariello, M., Chiriatti, M.A., Grieco, F., Perrotta, C., Capone, S., Rampino, P., Tristezza, M. \& Mita, G., 2014. Influence of autochthonous Saccharomyces cerevisiae strains on volatile profile of Negroamaro wines. LWT - Food Sci. Technol. 58, 35-48.

Velázquez, R., Zamora, E., Álvarez, M., Álvarez, M.L. \& Ramírez, M., 2016. Using mixed inocula of Saccharomyces cerevisiae killer strains to improve the quality of traditional sparkling-wine. Food Microbiol. 59, 150160

Vilela, A., Schuller, D., Mendes-Faia, A. \& Corte-Real, M., 2013. Reduction of volatile acidity of acidic wines by immobilized Saccharomyces cerevisiae cells. Appl. Microbiol. Biotechnol. 97, 4991-5000.

Villalba, M.L., Susana Sáez, J., Del Monaco, S., Lopes, C.A. \& Sangorrín, M.P., 2016. TdKT, a new killer toxin produced by Torulaspora delbrueckii effective against wine spoilage yeasts. Int. J. Food Microbiol. 217, 94-100. 